\title{
Pemikiran Ibnu Khaldun Tentang Kebijakan Fiskal Khusus Pajak dan Relevansinya Dalam Menghadapi Resesi di Indonesia
}

\author{
Dwita Sukmalia $^{1}$, Ida Yuliana Saputri ${ }^{2}$, Nurul Hak ${ }^{3}$, Amimah Oktarina ${ }^{4}$ \\ Institut Agama Islam Negeri Bengkulu \\ dwitasukmaliaa@gmail.com ${ }^{1}$, idayuli30ana@gmail.com ${ }^{2}$,nurul_hak@iainbengkulu.ac.id ${ }^{3}$, \\ amimahoktarina@iainbengkulu.ac.id ${ }^{\overline{4}}$
}

Abstract

Keywords

Abstrak

\begin{abstract}
Ibn Khaldun is an Islamic scholar with various works, especially in the muqaddimah book which explains the principles of taxation. According to Ibn Khaldun, the imposition of low taxes on the people will make the people more incentivized to do business and develop the business world. On the other hand, the imposition of high taxes on the people will be reluctant to pay taxes so that the production done by the people will decrease and affect the tax revenue itself. The purpose of this study was to determine the relationship between Ibn Khaldun's theory and the current downturn in economic growth. This research method is library research research with a descriptive qualitative approach with the data source used is secondary data consisting of the book "muqaddimah" and other theories derived from books, journals, and official websites that are relevant to the research. The data that has been collected is analyzed using the Content Analysis Method. This study concludes that Ibn Khaldun's thoughts are very relevant when applied in facing the recession in Indonesia
\end{abstract}

Ibn Khaldun, Taxes, Fiscal Policy, Recession

Ibnu khaldun merupakan cendikiawan islam dengan berbagai karya terutama dalam buku muqaddimah yang menjelaskan prinsip perpajakan. Menurut Ibnu khaldun, pembebanan pajak yang rendah kepada rakyat akan membuat rakyat lebih insentif berusaha dan mengembangkan dunia usaha. Sebaliknya pembebanan pajak yang tinggi kepada rakyat akan enggan membayar pajak sehingga produksi yang dilakukan rakyat akan berkurang dan mempengaruhi penerimaan pajak itu sendiri. Tujuan dari penelitian ini adalah untuk mengetahui keterkaitan teori Ibnu khaldun dengan pertumbuhan perekonomian yang menurun pada saat ini. Metode penelitian ini adalah penelitian library research dengan pendekatan kualitatif kearah deksriptif dengan sumber data yang digunakan adalah data sekunder terdiri dari buku "muqaddimah" dan teori lain berasal dari buku, jurnal, dan web resmi yang relevan terhadap penelitian. Data yang telah terkumpul di analisis menggunakan Metode Content Analysis. Penelitian ini menyimpulkan bahwa Pemikiran Ibnu Khaldun sangat relevan jika diterapkan dalam menghadapi resesi di Indonesia.

Kata Kunci : Ibnu Khaldun, Pajak, Kebijakan Fiskal, Resesi

\section{A. Pendahuluan}

Berdasarkan data BPS mencatat ekonomi Indonesia pada kuartal I-2020 sebesar 2,97\%. Pertumbuhan ekonomi Indonesia mengalami perlambatan dibandingkan kuartal sebelumnya sebesar 5,07\%. ${ }^{1}$ Pada kuartal II-2020 ekonomi Indonesia mengalami kontraksi sebesar 5,32\%. ${ }^{2}$ Dengan ini menandakan negara akan memasuki resesi yang ditandai dengan penurunan pertumbuhan ekonomi secara berturut-turut selama dua kuartal ${ }^{3}$ Penerimaan pajak hingga agustus $2020 \mathrm{Rp} 676,9 \mathrm{~T}$ atau 56,5\% dari target penerimaan pajak, maka penerimaan pajak sampai akhir agustus adalah $15,6 \%$ dalam penerimaan pajak yang penurunan sangat tajam adalah pajak PPH migas dari sektor usaha mengalami penurunan.

${ }^{1}$ Badan Pusat Statistik, "Pertumbuhan Ekonomi Indonesia Triwulan IV-2019," Www.Bps.Go.Id, last modified 2019, https://www.bps.go.id/pressrelease/2020/02/05/1755/ekonomi-indonesia-2019-tumbuh-5-02persen.html.

${ }^{2}$ Badan Pusat Statistik, "Pertumbuhan Ekonomi Indonesia Triwulan I-2020," Pertumbuhan Ekonomi Indonesia Triwulan IV-2019.

${ }^{3}$ M Farid, "Krisis Politik Dan Resesi Ekonomi Hong Kong (2019) Dalam Perspektif Konstelasi Global Dan Potensi Dampaknya Bagi Indonesia,” Jurnal Kajian Lemhannas RI, no. 40 (2019): 38. 
Kebijakan fiskal merupakan suatu kebijakan yang dilakukan pemerintah yang berkaitan dengan pendapatan dan pengeluaran negara yang di maksudkan untuk mengendalikan stabilitas ekonomi dan mendorong pertumbuhan ekonomi. ${ }^{4}$ Dalam Perekonomian, kebijakan fiskal idealnya bersifat automatic stabilizer. Yang dimana perekonomian negara yang mengalami ekspansif maka pengeluaran negara akan bertambah dan penerimaan pajak oleh pemerintah berkurang. Sedangkan pada saat perekonomian kontraktif, pemerintah melakukan peningkatan penerimaan tarif pajak dan pengurangan pengeluaran pemerintah. ${ }^{5}$

Ibnu Khaldun berpendapat Pembebanan pajak yang begitu besar akan mebuat kegiatan ekonomi menjadi rendah yang akan berdampak pada perekonomian negara itu sendiri. Konsep pajak yang ditetapkan tidak selaras dengan tujuan awal hal ini akan berdampak pada stabilitas dan pertumbuhan ekonomi. ${ }^{6}$ khaldun telah menekankan prinsip perpajakan yaitu "harus diketahui bahwa pada awal dinasti pajak menghasilkan pendapatan yang besar dari pembebanan yang kecil. Pada akhir dinasti pajak menghasilkan pendapatan yang kecil dari pembebanan yang besar. Pada awalnya pendapatan pajak rendah, bila dibebankan pajak atas penduduk rendah, penduduk memiliki tenaga dan hastrat untuk bekerja. Perusahaan kultur berkembang dan naik karena pajak yang rendah menghasilkan kepuasan. Bila perusahaan kultur berkembang jumlah iuran individu dan pembebanan pajak naik akibatnya pendapatan pajak naik. ${ }^{7}$

Ibnu Khaldun berpendapat Pembebanan pajak yang begitu besar akan mebuat kegiatan ekonomi menjadi rendah yang akan berdampak pada perekonomian negara itu sendiri. Konsep pajak yang ditetapkan tidak selaras dengan tujuan awal hal ini akan berdampak pada stabilitas dan pertumbuhan ekonomi. ${ }^{8}$ khaldun telah menekankan prinsip perpajakan yaitu "harus diketahui bahwa pada awal dinasti pajak menghasilkan pendapatan yang besar dari pembebanan yang kecil. Pada akhir dinasti pajak menghasilkan pendapatan yang kecil dari pembebanan yang besar. Pada awalnya pendapatan pajak rendah, bila dibebankan pajak atas penduduk rendah, penduduk memiliki tenaga dan hastrat untuk bekerja. Perusahaan kultur berkembang dan naik karena pajak yang rendah menghasilkan kepuasan. Bila perusahaan kultur berkembang jumlah iuran individu dan pembebanan pajak naik akibatnya pendapatan pajak naik. ${ }^{9}$

Berdasarkan masalah dan pemikiran yang diuraikan diatas maka penulis tertarik membahas teori ibnu khaldun tentang pajak dengan melakukan penelitian mengenai bagaimana keterkaitan teori pajak persektif ibnu khaldun terhadap resesi yang dihadapi Indonesia.

\section{B. Metode Penelitian}

Penelitian ini merupakan penelitian library research (penelitian kepustakaan). Pendekatan kualitatif kearah deskriptif dengan cara mengambarkan dan mengaitkan teori ibnu khaldun

\footnotetext{
${ }^{4}$ Fahdil Amin Al Hasan And Rifqi Qowiyul Iman, "Instrument Pajak Dalam Kebijakan Fiskal Perspektif Ekonomi Islam (Tinjauan Kritis Terhadap Penerimaan Perpajakan Dalam Rapbn 2017),” Adliya: Jurnal Hukum Dan Kemanusiaan 11, No. 2 (2017): 167.

${ }^{5}$ Novi Mubyarto, "Strategi Kebijakan Fiskal Dalam Merespon Siklus Ekonomi (Pelajaran Dari Kisah Nabi Yusuf Dan Pendapat Ibnu Khaldun)," Nalar Fiqh 10, No. 2 (2014): 2.

${ }^{6}$ Agustri, "Pajak Sebagai Salah Satu Konsep Keuangan Publik Perspektif Ibn Khaldun," Tamaddun Ummah: Jurnal Keislaman, Kemasyarakatan, Dan Pembangunan 1, No. 1 (2015): 3.

${ }^{7}$ Adiwarman A Karim, Sejarah Pemikiran Ekonomi Islam, keempat. (Depok: PT. Raja Grafindo Persada, 2019): 348

${ }^{8}$ Agustri, "Pajak Sebagai Salah Satu Konsep Keuangan Publik Perspektif Ibn Khaldun."

${ }^{9}$ Karim, Sejarah Pemikiran Ekonomi Islam.
} 
tentang pajak dengan kejadian atau fenomena resesi yang akan terjadi di indonesia. Sumber data yang digunakan adalah sumber data sekunder dengan membaca dan menelaah serta menganalisis literatur yang berasal dari buku Muqadimmah Ibnu Khaldun, jurnal dan web resmi yang mengeluarkan informasi-informasi yang relevan terhadap penelitian. Data yang telah terkumpul di analisis menggunakan Metode Content Analysis.

\section{Hasil dan Pembahasan}

\section{Teori Ibnu Khaldun Tentang Pajak}

Abdurrahman Abu Zaid Waliuddin Ibnu Khaldun lebih dikenal dengan Ibnu Khaldun lahir di Tunisia pada bulan Ramadhan $732 \mathrm{H}$ atau $1332 \mathrm{M}$. Berdasarkan keturunannya, Ibnu khaldun dengan Wail Bin Hajar seorang sahabat Nabi Muhammad SAW masih bersilsilah. Ibnu khaldun mempunyai nenek moyang yang berasal dari Hadrmaut. Ayahnya Abu Abdullah Muhammad berkecimpung dalam bidang politik, kemudian mengundurkan diri dan menekuni ilmu pengetahuan dan kesufian. Ibnu Khaldun wafat di Kairo, Mesir, pada 25 Ramadhan 808 H/1406 M. ${ }^{10}$

Dijelaskan dalam bukunya Ibnu Khaldun berjudul Muqaddimah, teori perpajakan merupakan salah satu karya yang memberikan kontribusi dalam pemikiran ekonomi dimana teori ini lebih dahulu dibandingkan teori Adam Smith tentang Canons of taxation atau kaidahkaidah perpajakan (Persamaan, Kepastiaan, Keyakinan pembayaran dan ekonomi dalam pengumpulan). Dalam menjalankan tugasnya terhadap warga negara dan perekonomian masing- masing negara membutuhkan sumber daya yang dikumpulkan pemerintah dengan berbagai cara yang paling penting diantaranya adalah pajak yang menjadi fokus Ibnu Khaldun. Ibnu Khaldun mendukung keseimbangan politik dan anggaran pendapatan dan pengeluaran seimbang di masing-masing negara. Jika pendapatan bukan pengeluaran besar, penduduk menjadi lebih menguntungkan dan negara akan mengalami pertumbuhan. ${ }^{11}$

Dalam sebuah negara, pajak yang dibebankan kepada rakyat kecil maka akan mendorong rakyat akan terus aktif dalam melakukan bisnis sehingga dapat meningkatkan produksi dan populasi dengan semakin banyaknya bisnis akan membuat penerimaan pajak menjadi meningkat dan sebaliknya pajak yang tinggi akan membuat masyarakat enggan melakukan bisnis yang akan mempengaruhi produksi dan populasi sehingga hal ini akan mempengaruhi perekonomian suatu negara. Pada akhirnya, jika beban pajak yang dibebankan kepada masyarakat begitu besar, maka secara bertahap kegiatan ekonomi akan melambat dan masyarakat akan malas untuk membuka kegiatan usaha yang produktif. ${ }^{12}$

Ibnu khaldun menganalisis dampak pengeluaran pemerintah terhadap perekonomian. Dalam pengertian ini, ia adalah pelopor Keynes. Dia mengatakan "peningkatan belanja pemerintah akan menyebabkan penurunan penerimaan pajak. Alasannya, negara merupakan pasar terbesar bagi dunia dan sumber peradaban. Jika penguasa mengakumulasi penerimaan pajak atau hasil penerimaan ini tidak terlihat dan tidak membelanjakannya untuk tujuan yang dimaksudkan, maka dana yang disimpan di pengadilan dan para pendukungnya akan berkurang". ${ }^{13}$ Dengan demikian, jika penguasa menahannya untuk belanja, rakyat akan

\footnotetext{
${ }^{10}$ Ibnu Khaldun, Ibnu Khaldun Mukaddimah (TERJEMEHAN), ed. Masturi Ilham, Malik Supar, and Abidun Zuhri (Jakarta Timur: PUSTAKA AL-KAUTSAR, 2001).

${ }^{11}$ Abdul Azim Islahi, "Ibn Khaldun' s Theory of Taxation and Its Relevance Today Ibn Khaldun' s Theory of Taxation and Its Relevance Today," Turkish Journal of Islamic Economics, no. August (2015): 6.

${ }_{12}$ Agustri, "Pajak Sebagai Salah Satu Konsep Keuangan Publik Perspektif Ibn Khaldun."

${ }^{13}$ Khaldun, Ibnu Khaldun Mukaddimah (TERJEMEHAN).
} 
dijauhkan padanya. Jika para pemimpin sebuah negara menahan dan menyimpan uang yang dikumpulkan dari pajak, dan mereka tidak memiliki uang untuk dibelanjakan, maka jumlah uang yang ada di tangan pemimpin dan pegawai pemerintah akan berkurang. Hal ini dikarenakan mereka harus membayar gaji aparatur negara. Hal tersebut akan berdampak pada perekonomian masyarakat dibawahnya yang menjalankan perekonomian tersebut. Pendapatan pemerintah dari pajak yang dikumpulkan dari pedagang juga akan berkurang. Dan negara akan menderita karena sedikit pendapatan dari pajak. ${ }^{14}$ Oleh karena itu pemerintah harus membangun kota dengan cepat, juga pemerintah harus dekat dan mengayomi rakyat dengan cara memberikan subsidi modal terhadap rakyat dengan begitu pajak yang didapatkan akan bertambah.

Seiring perkembangan negara dan pergantian kekuasaan akan muncul tradisi baru dalam kemewahan dan kenikmatan yang dirasakan. Hal tersebut membuat pengeluaran meningkat sehingga pembebanan pajak meningkat dan yang menjadi sasaran atas pembebanan pajak adalah rakyat, para pembajak tanah, petani, dan orang-orang yang menjadi sasaran wajib lainnya. Namun pembebanan melebihi batas wajar sehingga rakyat merasa terbeban akan pajak. Pembebanan pajak yang begitu besar akan membuat kegiatan ekonomi menjadi rendah yang akan berdampak kepada perekonomian negara itu sendiri. ${ }^{15}$ Ibnu Khaldun melihat kemewahan sebagai penghalang untuk mencapai kemakmuran. Kemewahan juga akan menyebabkan bangsa akan terlena dalam menikmati keuntungan yang diraih. Dengan adanya kemewahan yang dilakukan pemerintah membuat tarif pajak naik dan berdampak terhadap pemasukan pajak yang menyebabkan rakyat berasumsi bahwa pemerintah tidak bijaksana dalam mengatur penerimaan dan pengeluaran pajak. ${ }^{16}$

Dalam pandangan Ibnu khaldun katanya dalam kitab Muqaddimah "pada awal berdirinya suatu negara, ada banyak pajak dan sebagian kecil dari pajak itu dibebankan pada individu" kemudian ibnu khaldun juga mengatakan "bahwa pada akhir negara, jumlah pajaknya kecil dan bahkan banyak pungutan yang dibebankan pada individu". ${ }^{17}$

Begitu banyaknya pajak yang diberlakukan oleh pemerintah kepada masyarakat menjadi penyebab konsep pajak yang tidak sesuai lagi dengan tujuan awal dari pemungutan pajak dan memberi dampak negatif terhadap produksi. Konsep pajak yang ditetapkan tidak selaras dengan tujuan awal akan berdampak pada stabilitas dan pertumbuhan ekonomi. Pemerintah dan rakyat harus ikut andil dalam mengawasi pengelolaan pajak agar tidak terjadi penyelewengan pengeluaran pajak tetapi pemerintah juga harus ikut campur dalam upaya peningkatan pajak. ${ }^{18}$

Ibnu Khaldun menyatakan bahwa, jika pemerintah ikut serta dalam perdagangan dapat menyebabkan kerusakan struktur fiskal jika maksud dari pemerintah adalah untuk meningkatkan pendapatan sendiri maka masyarakat akan gelisah dalam menjalankan usahanya dan banyak perasaan khawatir karena bersaing dengan kepala negara sendiri. Hal ini dikarenakan kepala negara dalam melakukan bisnis menggunakan sistem monopoli. Menurut ibnu khaldun, bahwa keuntungan yang diperoleh dari praktik monopoli tidak sebanding dengan penurunan nilai pajak yang diperoleh negara. Sehingga secara tidak langsung

\footnotetext{
${ }^{14}$ Umer Chapra, Masa Depan Ilmu Ekonomi Sebuah Tinjauan Isalam (Jakarta: Gema Insani Press, 2001).

${ }^{15}$ Khaldun, Ibnu Khaldun Mukaddimah (TERJEMEHAN).

${ }^{16}$ Agustri, "Pajak Sebagai Salah Satu Konsep Keuangan Publik Perspektif Ibn Khaldun."

${ }^{17}$ Khaldun, Ibnu Khaldun Mukaddimah (TERJEMEHAN).

${ }^{18}$ Agustri, "Pajak Sebagai Salah Satu Konsep Keuangan Publik Perspektif Ibn Khaldun."
} 
pemerintah mengurangi pendapatan pajak yang sebenarnya dihasilkan oleh petani dan pedangangan ${ }^{19}$

Jadi, Ibnu Khaldun menawarkan konsep keadilan dalam perpajakan. Dimana dalam konsep ibnu khaldun membatasi peran pemerintah tidak terlalu jauh dalam masalah pasar. Termasuk dalam masalah perpajakan. Pemungutan pajak berdasarkan keadilan. Pajak yang adil amat berpengaruh pada kesejahteraan suatu negara. Kemakmuran cenderung beredar antara masyarakat dan pemerintah dari pemerintah ke masyarakat dan masyarakat ke pemerintah, sehingga pemerintah tidak bisa menjauhkan belanja negera dari masyarakat karena akan menyebabkan masyarakat menjauh dari pemerintah. Kewajiban pajak berbeda antara satu individu dengan individu lainnya, jika terdapat perbedaan ruang, waktu dan tempat. $^{20}$

\section{Pajak Sebagai Instrumen Kebijakan Fiskal di Indonesia}

Kebijakan fiskal adalah kebijakan yang dilakukan pemerintah dalam penerimaan dan pengeluaran negara dalam upaya mendorong stabilitas ekonomi dan mendorong pertumbuhan ekonomi.. Kebijakan fiskal memiliki peran yang sangat penting dalam mendukung stabilitas ekonomi suatu negara yang dimaksudkan untuk mengendalikan stabilitas ekonomi dan mendorong pertumbuhan ekonomi. ${ }^{21}$ kebijakan fiskal di indonesia mengacu pada kebijakan pemerintah yang terbukti mengarahkan perekonomian suatu negera melalui pengeluaran serta penerimaan pemerintah. ${ }^{22}$ Tujuan Kebijakan fiskal yaitu:

a. Meningkatkan kesempatan kerja

Kebijakan fiskal dapat membuka lapangan kerja dan mengurangi pengangguran sehingga meningkatkan laju pertumbuhan ekonomi karena merupakan indikator kesejahteraan suatu negara. Untuk mengurangi pengangguran, pemerintah dan masyarakat harus ikut serta mengoptimalkan kemampuannya, salah satunya dalam bentuk UKM.

b. Meningkatkan dan Mendistribusikan Pendapatan Nasional

Adanya ketimpangan Pendapatan akan menyebabkan terganggunya stabilitas ekonomi suatu negara. Untuk mengatasi hal tersebut pemerintah dapat mengeluarkan kebijakan fiskal yang berkaitan dengan pengeluaran kebutuhan untuk masyarakat.

c. Investasi

Pemerintah dapat melakukan peningkatan laju investasi dalam pengoptimalan kegiatan investasi berbagai sektor swasta ataupun pemerintah yang berpeluang meningkatkan investasi untuk kebutuhan masyarakat

19 Jirhanuddin, Ahmad Dakhoir, and Sayri, "KONSEP PENGELOLAAN PAJAK YANG ADIL PERSPEKTIF IBNU KHALDUN,” Jurnal Al-Qardh 2, no. 2 (2016): 100.

${ }^{20}$ Agustri, "Pajak Sebagai Salah Satu Konsep Keuangan Publik Perspektif Ibn Khaldun."

${ }^{21}$ Desi Isnaini, "Peranan Kebijakan Fiskal Dalam Sebuah Negara," Al-Intaj 3, No. 1 (2017): 104.

${ }^{22}$ Nurlina and Zurjani, "Dampak Kebijakan Fiskal Dan Moneter Dalam Perekonomian Indonesia," JURNAL SAMUDRA EKONOMIKA 2, no. 2 (2018): 128. 


\section{d. Stabilitas Ekonomi}

Kebijakan fiskal adalah upaya pemerintah dalam mempertahankan stabilitas ekonomi suatu negara dengan cara efektivitas pendapatan dan efisiensi pengeluaran negara. ${ }^{23}$

Pajak adalah retribusi masyarakat kepada negara yang yang berdasarkan perundangundangan yang tidak dapat dibalas langsung dan digunakan untuk membiayai pengeluaran negara yang ditunjukkan bagi kemakmuran. Pemungutan pajak sangat diperlukan untuk membiayai anggaran dan pengeluaran negara. Penerimaan pajak pemerintah dipengaruhi oleh tingkat pendapatan, pajak juga dapat mempengaruhi perilaku produksi dan komsumsi masyarakat. Beberapa fungsi pajak yaitu: ${ }^{24}$

a. Fungsi anggaran

Sebagai sumber pendapatan negara, pajak berfungsi untuk membiayai pengeluaranpengeluaran negara. Untuk menjalankan negara dan melaksanakan pembangunan, negara membutuhkan biaya. Biaya ini diperoleh dari penerimaan pajak. Saat ini pajak digunakan untuk pembiayaan rutin seperti belanja pegawai, pembelian barang, pemeliharaan dan lain sebagainya.

b. Fungsi mengatur

Pemerintah dapat mengatur pertumbuhan ekonomi melalui kebijakaan pajak. Dengan fungsi pengaturan, pajak dapat digunakan sebagai alat untuk mencapai tujuan. Misalnya, untuk mendorong investasi, baik di dalam maupun luar negeri, disediakan fasilitas keringanan pajak. Untuk melindungi produksi dalam negeri, pemerintah menetapkan bea masuk yang tinggi untuk produk luar negeri.

c. Fungsi stabilitas

Dengan adanya pajak, maka pemerintah mempunyai dana untuk melaksanakan kebijakan yang berkaitan dengan stabilitas harga agar inflasi dapat dikendalikan, hal tersebut dapat dilakukan antara lain dengan mengatur peredaran uang, pemungutan pajak, penggunaan yang efektif dan efisien dalam pajak.

d. Fungsi redistribusi pendapatan

Pajak yang berhasil dihimpun oleh negara akan digunakan untuk membiayai semua kepentingan masyarakat, termasuk untuk membiayai pembangunan sehingga dapat membuka lapangan kerja yang pada akhirnya akan meningkatkan pendapatan masyarakat.

Secara dikotomis, fungsi pajak dibedakan menjadi 2 yaitu, fungsi budgetair pajak digunakan untuk memasukan pendapatan untuk membiayai pengeluaran pengeluaran negara guna membiayai pembangunan. ${ }^{25}$ Kebijakan pemerintah dalam perpajakan dengan menerapkan pengampunan pajak diharapkan akan menambah pajak yang terkumpul dalam

\footnotetext{
${ }^{23}$ Ina Heliany, "Peran Kebijakan Fiskal Dalam Mengatasi Resesi Ekonomi Di Indonesia," Prosiding Seminar Stiami 8, no. 1 (2021): 17-18.

${ }^{24}$ Nurlina and Zurjani, "Dampak Kebijakan Fiskal Dan Moneter Dalam Perekonomian Indonesia."

${ }^{25}$ F.C. Susila Adiyanta, "Fleksibilitas Pajak Sebagai Instrumen Kebijaksanaan Fiskal Untuk Mengantisipasi Krisis Ekonomi Sebagai Akibat Dampak Pandemi Covid-19," Administrative Law and Governance Journal 2, no. 1 (2020): 175.
} 
waktu yang singkat dan jumlah signifikan. Dengan kepatuhan masyarakat dalam membayar pajak dapat mengoptimalkan pendapatan pajak. ${ }^{26}$

Fungsi regulair kebijakan pemerintah dari sudut sosial dan ekonomi dimana tujuannya untuk mencapai kesejahteraan ekonomi yang adil dan merata dalam bidang hukum ekonomi sosial. Dalam hal ini pajak dijadikan pemerintah sebagai pengatur dalam mencapai tujuan tertentu. Tujuan yang ingin dituju dari program pengampunan pajak secara regulair yaitu mempercepat dan restrukturisasi pertumbuhan ekonomi yang berdampak pada kenaikan investasi, penurunan tingkat suku bunga dan perbaikan nilai tukar rupiah. ${ }^{27}$

\section{Relevansi Pemikiran Ibnu Khaldun Tentang Pajak dalam Menghadapi Resesi di Indonesia}

Dijelaskan dalam buku Muqaddimah Ibnu Khaldun bahwa, Dalam sebuah negara tingkat pajak yang dibebankan rendah akan memiliki dampak insentif terhadap kegiatan bisnis yang secara alamiah mendorong kegiatan perdagangan yang membuat meningkatnya pendapatan pajak disertai dengan kesejahteraan ekonomi. Bila beban pajak dibebankan kepada masyarakat besar, maka kegiatan perekonomian lambat laun akan mengalami stagnasi sehingga masyarakat akan malas untuk membuka kegiatan usaha yang produktif, pada akhirnya kegiatan ekonomi akan berhenti dan negara akan mengalami kehancuran. ${ }^{28}$

Perekonomian yang awalnya makmur mendapatkan pajak dalam jumlah dan tarif yang dibebankan rendah, sementara perekonomian yang mengalami depresi akan menghasilkan pajak yang lebih rendah dengan tarif pajak yang lebih tinggi. Hal tersebut terjadi karena rakyat tidak mendapat keadilan dalam kemakmuran yang menyebabkan rakyat enggan untuk berkerja dan berdampak pada usaha mereka dalam berproduksi. Dengan hal tersebut pasar akan mati dan kondisi rakyat akan semakin sengsara serta penerimaan pajak akan menurun.

Kondisi Indonesia telah mengalami resesi ekonomi berdasarkan penurunan pertumbuhan ekonomi selama dua kuartal berturut-turut. Dampak yang dirasakan adalah meningkatnya angka pengganguran dan masyarakat yang tidak memiliki penghasilan. Pajak sebagai sektor pendapatan negara terbesar pastinya akan berdampak lebih karena berkurangnya jumlah terhutang pajak menyebabkan penyumbatan pajak sehingga insentif masyarakat membayar pajak berkurang karena kurangnya penghasilan. ${ }^{29}$

Dengan kondisi tersebut membuat pemerintah mengeluarkan kebijakan fiskal yang tepat dalam upaya pencapaian pertumbuhan ekonomi yang tinggi. Dalam menghadapi resesi kebijakan fiskal ekspansif digunakan pemerintah sebagai langkah untuk mengatasi masalah tersebut, dimana kebijakan fiskal ekspansif pemerintah akan meningkatkan nilai belanja pengeluaran daripada penerimaan. ${ }^{30}$ Dari sisi penerimaan pemerintah banyak mengeluarkan insentif pajak untuk wajib pajak yang terkena dampak resesi. Dari sisi pengeluaran pemerintah memfokuskan kepada pemberian bantuan darurat kepada populasi yang rentan dan bisnis yang terkena dampak. Hal tersebut dimaksudkan untuk mendorong stimulus

\footnotetext{
${ }^{26}$ Agus Iwan Kesuma, "Pengampunan Pajak (Tax Amnesty) Sebagai Upaya Optimalisasi Fungsi Pajak," Inovasi : Jurnal Ekonomi Keuangan, Dan Manajemen 12, No. 2 (2016): 278.

${ }^{27}$ Ibid.

${ }^{28}$ Agustri, "Pajak Sebagai Salah Satu Konsep Keuangan Publik Perspektif Ibn Khaldun."

${ }^{29}$ M. Citra Ramadhan, "Jurnal Ilmiah Penegakan Hukum," Pemberian Keringanan Pajak di Masa Resesi Ekonom Berdasarkan Perspektif Islam 7, no. 2 (2020): 135.

${ }^{30}$ Nurlina and Zurjani, "Dampak Kebijakan Fiskal Dan Moneter Dalam Perekonomian Indonesia."
} 
perekonomian agar tetap berjalan. ${ }^{31}$ Dalam upaya mengatasi meningkatnya angka pengganguran pemerintah membentuk program jaringan pengamanan sosial yaitu "Kartu Pra Kerja" yang ditujukan kepada masyarakat yang terkena PHK. ${ }^{32}$

Pemikiran ibnu Khaldun sangat relevan dalam menghadapi resesi dimana sistem penerimaan pajak haruslah diarahkan kepada prinsip keadilan kedalam pemungutan pajak. ${ }^{33}$ Ibnu Khaldun mengajukan obat resesi ekonomi yaitu dengan mengecilkan pajak dan meningkatkan pengeluaran. $^{34}$

Ibn Khaldun sangat menekankan konsep pajak yang adil karena ini adalah hak sebagai warga negara. masyarakat memberikan kewajibannya untuk membayar pajak maka mereka akan mendapatkan hak dari pemerintah. Jika masyarakat hanya mendapatkan hak dan pemerintah hanya memenuhi kewajiban maka keduanya akan dirugikan, sehingga diperlukan keseimbangan antara hak dan kewajiban agar mendapatkan kemaslahatan bersama. di sisi lain keadilan dalam perpajakan mengarahkan kepada kemampuan warga negara dalam membayar pajak dan pengeluaran pajak harus digunakan untuk kebutuhan masyarakat atau pembangunan negara.

\section{Simpulan}

Berdasarkan pembahasan tentang konsep pajak dalam pandangan ibnu khaldun kemudian dikaitkan pada kondisi resesi yang terjadi di Indonesia saat ini. Adanya keterkaitan pada pandangan ibnu khaldun ketika tingkat pajak yang dibebankan kepada masyarakat rendah akan memiliki dampak insentif terhadap kegiatan bisnis yang secara alamiah mendorong kegiatan perdagangan membuat meningkatnya pendapatan pajak disertai dengan kesejahteraan ekonomi. Dalam menghadapi resesi pemerintah mengeluarkan kebijakan fiskal ekspansif dimana kebijakan tersebut digunakan untuk meningkatkan nilai belanja pengeluaran selain itu pemerintah banyak mengeluarkan insentif pajak untuk wajib pajak yang terkena dampak resesi yang dimaksudkan untuk mendorong stimulus perekonomian agar tetap berjalan. Dapat dilihat bahwa kebijakan ini sejalan dengan pemikiran ibnu khaldun bahwa Ibnu Khaldun mengajukan obat resesi ekonomi yaitu dengan mengecilkan pajak dan meningkatkan pengeluaran.

\section{Daftar Pustaka}

Adiyanta, F.C. Susila. "Fleksibilitas Pajak Sebagai Instrumen Kebijaksanaan Fiskal Untuk Mengantisipasi Krisis Ekonomi Sebagai Akibat Dampak Pandemi Covid-19." Administrative Law and Governance Journal 2, no. 1 (2020): 175.

Agustri. "Pajak Sebagai Salah Satu Konsep Keuangan Publik Perspektif Ibn Khaldun." Tamaddun Ummah: Jurnal Keislaman, Kemasyarakatan, dan Pembangunan 1, no. 1 (2015): 3 .

Badan Pusat Statistik. "Pertumbuhan Ekonomi Indonesia Triwulan I-2020." Pertumbuhan Ekonomi Indonesia Triwulan IV-2019. Last modified 2020.

\footnotetext{
${ }^{31}$ Selena Riri Blandina, Alvin Noor Fitrian, and Wulan Septiyani, "Strategi Menghindarkan Indonesia Dari Ancaman Resesi Ekonomi Di Masa Pandemi” 7, no. 2 (2020): 187.

32 Ibid

${ }^{33}$ Dina Eva Silalahi and Rasinta Ria Ginting, "Strategi Kebijakan Fiskal Pemerintah Indonesia Dalam Menghadapi Dampak Pandemi COVID-19," Jesya (Jurnal Ekonomi \& Ekonomi Syariah) 3, no. 2 (2020): 156167.

${ }^{34}$ WIDI NOPIARDO, “Zakat Sebagai Ibadah Maliyah Ijtima’ Iyah Dalam Perspektif Ilmu Ekonomi Islam," JURIS (Jurnal Ilmiah Syariah) 14, no. 2 (2016): 216.
} 
https://www.bps.go.id/pressrelease/2020/02/05/1755/ekonomi-indonesia-2019tumbuh-5-02-persen.html.

—. "Pertumbuhan Ekonomi Indonesia Triwulan IV-2019." Www.Bps.Go.Id. Last modified 2019. https://www.bps.go.id/pressrelease/2020/02/05/1755/ekonomiindonesia-2019-tumbuh-5-02-persen.html.

Blandina, Selena Riri, Alvin Noor Fitrian, and Wulan Septiyani. "Strategi Menghindarkan Indonesia Dari Ancaman Resesi Ekonomi Di Masa Pandemi” 7, no. 2 (2020): 187.

Chapra, Umer. Masa Depan Ilmu Ekonomi Sebuah Tinjauan Isalam. Jakarta: Gema Insani Press, 2001.

Farid, M. "Krisis Politik Dan Resesi Ekonomi Hong Kong (2019) Dalam Perspektif Konstelasi Global Dan Potensi Dampaknya Bagi Indonesia." Jurnal Kajian $\begin{array}{lllll}\text { Lemhannas } & R I, & \text { no. } & 40 & \text { (2019): }\end{array}$ http://jurnal.lemhannas.go.id/index.php/jkl/article/view/110.

Al Hasan, Fahdil Amin, and Rifqi Qowiyul Iman. "INSTRUMENT PAJAK DALAM KEBIJAKAN FISKAL PERSPEKTIF EKONOMI ISLAM (Tinjauan Kritis Terhadap Penerimaan Perpajakan Dalam RAPBN 2017)." ADLIYA: Jurnal Hukum dan Kemanusiaan 11, no. 2 (2017): 167.

Heliany, Ina. "Peran Kebijakan Fiskal Dalam Mengatasi Resesi Ekonomi Di Indonesia." Prosiding Seminar Stiami 8, no. 1 (2021): 17-18.

Islahi, Abdul Azim. "Ibn Khaldun' s Theory of Taxation and Its Relevance Today Ibn Khaldun' s Theory of Taxation and Its Relevance Today." Turkish Journal of Islamic Economics, no. August (2015): 6.

Isnaini, Desi. "PERANAN KEBIJAKAN FISKAL DALAM SEBUAH NEGARA." $A L$ INTAJ 3, no. 1 (2017): 104.

Jirhanuddin, Ahmad Dakhoir, and Sayri. "KONSEP PENGELOLAAN PAJAK YANG ADIL PERSPEKTIF IBNU KHALDUN.” Jurnal Al-Qardh 2, no. 2 (2016): 100.

Karim, Adiwarman A. Sejarah Pemikiran Ekonomi Islam. Keempat. Depok: PT. Raja Grafindo Persada, 2019.

Kesuma, Agus Iwan. "PENGAMPUNAN PAJAK (TAX AMNESTY) SEBAGAI UPAYA OPTIMALISASI FUNGSI PAJAK." INOVASI : Jurnal Ekonomi Keuangan, dan Manajemen 12, no. 2 (2016): 278.

Khaldun, Ibnu. Ibnu Khaldun Mukaddimah (TERJEMEHAN). Edited by Masturi Ilham, Malik Supar, and Abidun Zuhri. Jakarta Timur: PUSTAKA AL-KAUTSAR, 2001.

Mubyarto, Novi. "STRATEGI KEBIJAKAN FISKAL DALAM MERESPON SIKLUS EKONOMI (Pelajaran Dari Kisah Nabi Yusuf Dan Pendapat Ibnu Khaldun)." NALAR FIQH 10, no. 2 (2014): 2.

NOPIARDO, WIDI. 'Zakat Sebagai Ibadah Maliyah Ijtima'Iyah Dalam Perspektif Ilmu Ekonomi Islam.” JURIS (Jurnal Ilmiah Syariah) 14, no. 2 (2016): 216. 
Dwita Sukmalia, Ida Yuliana, Nurul Hak, Amimah Oktarina, $\quad$ Pemikiran Ibnu Khaldun Tentang...

Nurlina, and Zurjani. "Dampak Kebijakan Fiskal Dan Moneter Dalam Perekonomian Indonesia." JURNAL SAMUDRA EKONOMIKA 2, no. 2 (2018): 128.

Ramadhan, M. Citra. "Jurnal Ilmiah Penegakan Hukum.” Pemberian Keringanan Pajak di Masa Resesi Ekonom Berdasarkan Perspektif Islam 7, no. 2 (2020): 135.

Silalahi, Dina Eva, and Rasinta Ria Ginting. "Strategi Kebijakan Fiskal Pemerintah Indonesia Dalam Menghadapi Dampak Pandemi COVID-19." Jesya (Jurnal Ekonomi \& Ekonomi Syariah) 3, no. 2 (2020): 156-167. 